\title{
Report on chloroquine and dapsone in the treatment of rheumatoid arthritis: a 6-month comparative study
}

\author{
P. D. FOWLER,$^{1} \mathrm{M}$. F. SHADFORTH $,^{1} \mathrm{P} \cdot \mathrm{R} \cdot \mathrm{CROOK},{ }^{1}{ }^{*}$ AND A. LAWTON ${ }^{2}$ \\ From the ${ }^{1}$ Staffordshire Rheumatology Centre, Haywood Hospital, Stoke on Trent, and the ${ }^{2}$ Research \\ Laboratories, North Staffordshire Medical Institute, Stoke on Trent
}

SUMMARY A controlled study compared 6 months' treatment of 60 patients with rheumatoid arthritis (RA). Half were randomly allocated to treatment with chloroquine $250 \mathrm{mg}$ daily, the other half dapsone $100 \mathrm{mg}$ daily $(50 \mathrm{mg} /$ day for the first 7 days) following a one-month run-in assessment period. All patients had active or progressing disease. Both treatment groups showed significant improvement in morning stiffness, number of painful joints, pain scores, Ritchie index, and proximal interphalangeal joint size, and the chloroquine group alone in grip strength. Laboratory tests showed significant decreases in erythrocyte sedimentation rate, C-reactive protein, and total serum protein levels, with significant increase in serum albumin in the dapsone group, where there was a significant mean drop in haemoglobin $(<1 \mathrm{~g} / \mathrm{dl})$ and a rise in serum bilirubin, associated with its haemolytic effect. $X$-ray erosion scores were not significantly affected. The clinical and laboratory responses became evident by the time of the 2-month assessment. Criteria for clinical and laboratory improvement were defined, according to which there were $21 / 26$ improvers in the chloroquine group and 12/29 in the dapsone group. It is concluded that although both are effective preparations, chloroquine showed a significantly higher improvement rate and was certainly better tolerated. It is the preferred treatment for patients with active or progressive disease not controlled by nonsteroidal anti-inflammatory drugs, with dapsone as an alternative for patients who fail to respond to or cannot tolerate chloroquine.

Antimalarials had been used in the treatment of rheumatoid arthritis following the observation in 1951 that patients with discoid lupus and rheumatoid arthritis showed improvement in their arthritis when treated with mepacrine. Dapsone was first reported to be useful by McConkey et al. ${ }^{1}$ in 1976 . Although the 2 substances are indicated for patients with disease of similar severity, we have not been able to trace any controlled comparative studies or controlled studies of dapsone alone of duration longer than 14 weeks.

This communication reports the results during the first 6 months of an ongoing long-term comparison of the value of these drugs.

* Present address: Ashington Hospital, Northumberland.

Accepted for publication 20 June 1983.

Correspondence to Dr P. D. Fowler, Staffordshire Rheumatology Centre, Burslem Haywood and Tunstall War Memorial Hospital, High Lane, Burslem, Stoke on Trent ST6 7AG.

\section{Patients and Methods}

Patient selection and treatment allocation. All patients fulfilled the American Rheumatism Association criteria for probable, definite, or classical rheumatoid arthritis (RA). Exclusion criteria included administration of a disease-modifying drug within the previous 3 months and pregnancy. Admission criteria were failure to respond to NSAI drugs, or progression of disease as shown by increasing clinical, laboratory, or $x$-ray features, or 'new' patients showing poor prognostic features early in the disease-e.g., nodules, high latex titre, or early erosive changes. In both instances the judgement was essentially clinical. The only mandatory criteria were: (i) many painful joints $(>6)$; (ii) high erythrocyte sedimentation rate (ESR) $(>30 \mathrm{~mm} / \mathrm{h})$ and/or C-reactive protein (CRP) $(>40 \mathrm{mg} / \mathrm{l})$.

Allocation within the group was random, either chloroquine $250 \mathrm{mg}$ daily or dapsone $50 \mathrm{mg}$ daily for 1 week, then $100 \mathrm{mg}$ daily. Routine nonsteroidal 
anti-inflammatory agents, analgesics or medications for other diseases, were continued unaltered.

Assessment of treatment effect. Assessments were done 4 weeks before therapy was started $(-4)$, the day it started $(0)$, and then at months 2,4 , and 6 , with additional laboratory tests at week -2 and the intermediate months. Latex and antinuclear factor (ANF) tests and $x$-rays were done initially and at 6 months.

Clinical assessments were of pain severity ( 0 to 4 and by visual analogue scale), duration ( 0 to 4$)$, and number of painful joints. Duration of morning stiffness was recorded and grip strength measured with a standard bag inflated to $30 \mathrm{mmHg}$, with 3 readings for each hand. The proximal interphalangeal joints were measured with the Geigy gauge and scored 0 to 3 for synovial swelling. The Ritchie index of joint tenderness was measured. General condition and change (better or worse) were both scored in 5 grades, and functional capacity classified on the Steinbrocker scale.

A side effect check list was completed before treatment, with an indirect questioning at each assessment.

Laboratory measurements included routine haematology, biochemistry, and urine analysis, ESR, C-reactive protein (CRP), and latex and ANF tests. $X$-rays of hands and feet were analysed for erosions and narrowing by the method of Sharp et al. ${ }^{2}$

Statistical methods. Confidence limits were drawn for variables at the -4 week and initial assessment, except in a few cases where the Mann-Whitney U test was used to assess initial differences between the groups.

The changes in magnitude or distribution over the 6 months from the initial assessment were tested for statistical significance by paired and unpaired $t$ tests. The Mann-Whitney U test and the chi-squared test was used for contingency table analysis.

\section{Results}

Sixty patients were admitted, 30 in each drug group. Initial comparison at week 0 (Table 1) showed the groups to be matched in most respects, the greater number of painful joints in the dapsone group being the only significant difference $(p<0 \cdot 05)$. There were some score changes during the 4-week run-in period, but none were statistically significant.

Withdrawals and drop-outs. During the 6-month study period 15 patients were withdrawn, 6 from the chloroquine and 9 from the dapsone treatment group (Table 2). Two men in the chloroquine group reported nausea and anorexia and were withdrawn after 4 and 6 weeks treatment respectively. In the dapsone group one patient was withdrawn with worsening bronchitis. Four patients developed
Table 1 Comparison of treatment groups

\begin{tabular}{lll}
\hline & Chloroquine & Dapsone \\
\hline Total & 30 & 30 \\
Males & 14 & 10 \\
Females & 16 & 20 \\
Mean age & $54 \mathrm{yr}$ & $54 \mathrm{yr}$ \\
Mean duration of RA & $5 \cdot 1 \mathrm{yr}$ & $5 \cdot 8 \mathrm{yr}$ \\
Mean no. of painful joints & $8 \cdot 1$ & $11 \cdot 2$ \\
Mean duration of morning & & \\
$\quad$ stiffness & $2 \cdot 6 \mathrm{~h}$ & $1 \cdot 5 \mathrm{~h}$ \\
Ritchie index & $12 \cdot 6$ & $14 \cdot 4$ \\
Mean ESR & $56 \mathrm{~mm} / \mathrm{h}$ & $56 \mathrm{~mm} / \mathrm{h}$ \\
Mean CRP & $43 \mathrm{mg} / \mathrm{l}$ & $43 \mathrm{mg} / 1$ \\
$X$-ray erosion score hands & 41 & 38 \\
& 14 & 17 \\
\hline
\end{tabular}

Table 2 Reasons for withdrawal of patients from the study

\begin{tabular}{lll}
\hline & Chloroquine group & Dapsone group \\
\hline Lack of efficacy & 0 & $4^{*}$ \\
Side effects & 2 & $5^{*}$ \\
Other reasons & 4 & 1 \\
Total & 6 & 9 \\
\hline
\end{tabular}

${ }^{*}$ One patient included in both criteria.

Table 3 Haemoglobin changes ( $g / d l)$ in dapsone group

\begin{tabular}{|c|c|c|c|}
\hline $\begin{array}{l}13 \cdot 1 \\
12 \cdot 8 \\
10 \cdot 8 \\
12 \cdot 1\end{array}$ & $\longrightarrow$ & $\begin{array}{r}10 \cdot 4 \\
9.1 \\
8 \cdot 8 \\
9 \cdot 2\end{array}$ & $\begin{array}{l}2 \text { weeks } \\
\text { one month* } \\
3 \text { weeks } \\
3 \text { months }\end{array}$ \\
\hline
\end{tabular}

* Re-exposure to dapsone after a recovery of haemoglobin resulted in similar effect.

haemolytic anaemia. The haemoglobin changes and time of withdrawal are shown in Table 3. One patient shown in this table also responded insufficiently. 'Other reasons' were not related to drug treatment, though 3 patients in the chloroquine group appeared to be responding.

Withdrawals because of poor response occurred at 2 months, 3 months, and 4 months ( 2 patients) respectively.

Clinical response at 6 months. The changes in mean values are shown in Table 4 . Both treatment groups showed significant improvement in the majority of both subjective and objective indices. Although there was greater mean improvement in the chloroquine group for all except the mean number of painful joints, there were no significant differences between the groups.

Laboratory indices of disease activity. As shown in Table 5, there were significant decreases in ESR and 
Table 4 Clinical responses

\begin{tabular}{|c|c|c|c|c|c|c|c|c|}
\hline & \multicolumn{8}{|c|}{ Mean values } \\
\hline & \multicolumn{4}{|c|}{ Chloroquine group ( $n=24)$} & \multicolumn{4}{|c|}{ Dapsone group $(n=21)$} \\
\hline & Initial & At 6 months & Change & $p$ & Initial & At 6 months & Change & $p$ \\
\hline $\begin{array}{l}\text { Morning stiffness (h) } \\
\text { No. of painful joints } \\
\text { Ritchie Index } \\
\text { VAS Score } \\
\text { † Grip strength (mmHg) } \\
\ddagger \text { PIP joint size mm }\end{array}$ & $\begin{array}{r}3.2 \\
7.9 \\
12.7 \\
40.8\end{array}$ & $\begin{array}{r}1 \cdot 0 \\
5.5 \\
8.5 \\
27 \cdot 2\end{array}$ & $\begin{array}{r}-2 \cdot 2 \\
-2 \cdot 4 \\
-4 \cdot 2 \\
-13 \cdot 6 \\
+63 \\
-1 \cdot 6\end{array}$ & $\begin{array}{r}* * * \\
* \\
* * \\
* * \\
* * \\
* * *\end{array}$ & $\begin{array}{r}1 \cdot 2 \\
10.2 \\
12.9 \\
40.8\end{array}$ & $\begin{array}{r}0.6 \\
6.4 \\
9.4 \\
31.9\end{array}$ & $\begin{array}{r}0.6 \\
3.8 \\
3.5 \\
8.9 \\
-12.7 \\
-1.4\end{array}$ & $\begin{array}{r}* * \\
* * * \\
* \\
* \\
\text { NS } \\
* *\end{array}$ \\
\hline
\end{tabular}

${ }^{*} p<0.05 .{ }^{* *} p<0.01 .{ }^{* * *} p<0.001$.

tMean change for 2 hands.

$\ddagger$ Mean change per finger.

Table 5 Changes in laboratory indices in patients completing the 6-month study period

\begin{tabular}{lllll}
\hline & \multicolumn{2}{l}{ Chloroquine group } & \multicolumn{2}{l}{ Dapsone group } \\
\hline No. of patients & 24 & & 21 & \\
$\begin{array}{l}\text { Mean fall in ESR mm/h } \\
\text { Mean fall in CRP mg/l }\end{array}$ & 21 & $* * *$ & 21 & $* *$ \\
$\begin{array}{l}\text { Haemoglobin g/dl } \\
\text { mean change }\end{array}$ & +0.26 & $\mathrm{NS}$ & -0.6 & $*$ \\
$\begin{array}{c}\text { Albumin g/l mean } \\
\text { change }\end{array}$ & +0.13 & $\mathrm{NS}$ & +1.35 & $*$ \\
$\begin{array}{c}\text { Total protein g/l } \\
\text { mean change }\end{array}$ & -3.88 & $* * *$ & -3.35 & $* *$ \\
$\begin{array}{c}\text { Serum bilirubin } \\
\text { mean change }\end{array}$ & +0.96 & $\mathrm{NS}$ & +2.05 & $*$ \\
\hline
\end{tabular}

${ }^{*} \mathrm{p}<0.05 .{ }^{* *} \mathrm{p}<0.01 .{ }^{* * *} \mathrm{p}<0.001$.

CRP in both groups, changes which were clinically as well as statistically meaningful. The dapsone group showed a significant mean fall in haemoglobin and mean rise in bilirubin, presumably related to its haemolytic effect.

Both groups showed significant decreases in total protein. Albumin was unchanged in the chloroquine group and increased significantly in the dapsone group. The total protein changes are presumably due to decrease in globulin production associated with disease improvement.

There were no significant changes in mean values for total white cell or platelet counts or in alkaline phosphatase levels.

$\mathrm{X}$-Rays. There were no clinically significant changes in the $x$-ray erosion scores.

Rate of response. The patients in both treatment groups showed steady and continuing clinical improvement over the 6-month observation period, already evident (particularly in the chloroquine group) by the time of the 2-month assessment.

The ESR and CRP values showed similar improvement. Haemoglobin increased slightly in the chloroquine group, but in the dapsone group showed a mean fall of more than $1 \mathrm{~g} / \mathrm{dl}$ due to the haemolytic effect of dapsone, with gradual recovery therafter as the arthritis improved. Alkaline phosphatase was not significantly affected in either group.

When assessing these changes it should be noted that 5 patients were withdrawn from the dapsone group because of lack of response and 4 because of haemolytic anaemia, whereas none were for either reason in the chloroquine group.

Responses of individual patients. Improvement was categorised as clinical, laboratory, or both. Clinical improvement was a response in 2 of 4 features, with no worsening in the other 2 , of a predetermined amount: morning stiffness, joint score, and Ritchie index by $50 \%$; visual analogue scale score by $40 \%$, with lesser amounts for those with low initial scores.

Laboratory improvement involved a decrease of at least 33\% in either ESR or CRP, with no increase in either.

As shown in Table 6, there were 8 patients in each group who showed clinical and laboratory improvement, but 13 in the chloroquine group compared with 4 in the dapsone group who showed clinical or laboratory improvement. The totals, $21 / 30$ for chloroquine and $12 / 30$ for dapsone, are significantly different $(\mathrm{p}<0.05)$.

Individual patient response to individual parameters. By plotting the initial score against the final

Table 6 Number of improvers in each category

\begin{tabular}{lccc}
\hline & $\begin{array}{l}\text { Chloroquine } \\
\text { group }\end{array}$ & $\begin{array}{l}\text { Dapsone } \\
\text { group }\end{array}$ \\
\hline Total & 30 & 30 & \\
Clinical and laboratory & 8 & 8 & \\
Clinical only & 5 & 0 & \\
Laboratory only & 8 & 4 & \\
Total & 21 & 12 & $\mathrm{p}<0.05$ \\
\hline
\end{tabular}




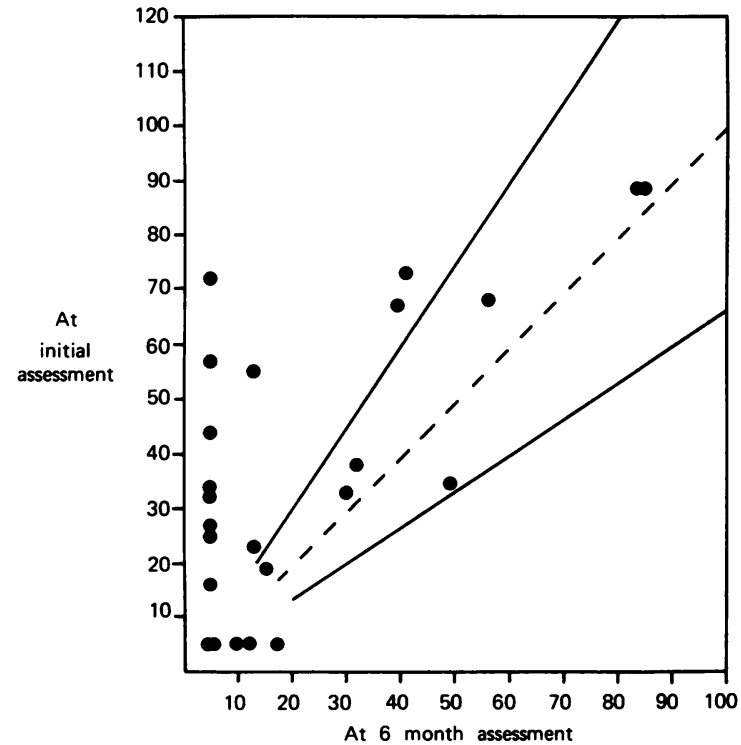

Fig. 1 Individual CRP levels at initial and 6-month assessment. Chloroquine group.

score and indicating the area of no clinically significant change we can obtain a rapid visual impression of response. As an example Figs. 1 and 2 show the changes in CRP levels. From this type of display improvers and worseners can be clearly identified,

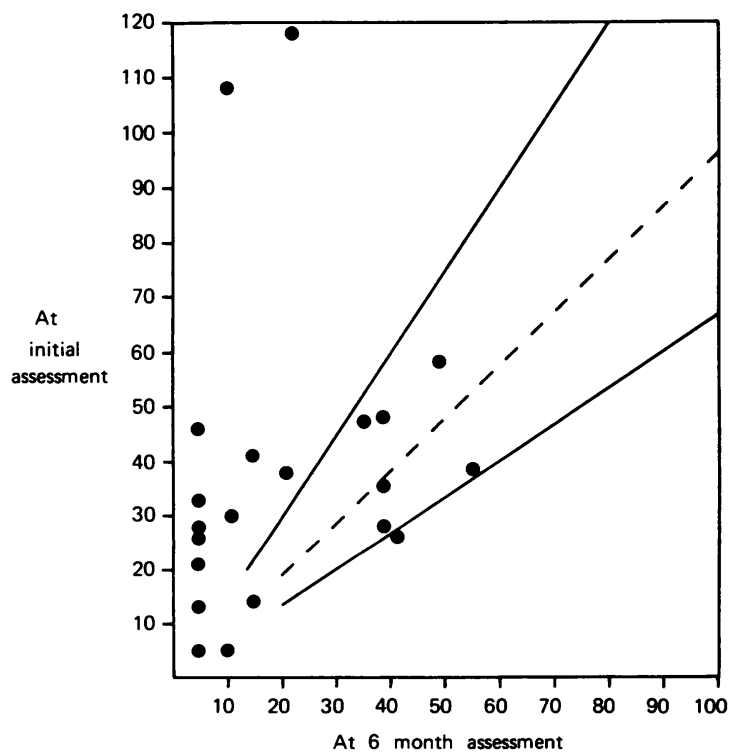

Fig. 2 Individual CRP levels at initial and 6-month assessment. Dapsone group. with 12 and 3 in the chloroquine, 11 and 2 in the dapsone group respectively. The diagrams for the other disease features are similar, showing only small differences in effect between the 2 treatment groups (though it must be noted that 4 patients on dapsone were excluded from the 6 month analysis because of 'poor response'). The fall in CRP from high levels to within the normal range $(<10 \mathrm{mg} / \mathrm{l})$ in a large proportion of patients in both treatment groups is particularly well illustrated.

\section{Discussion}

Our study has certainly demonstrated that both substances effectively relieve the symptoms, clinical signs, and biological parameters of rheumatoid arthritis, with group responses being evident by 2 months and continuing up to 6 months. The major significant difference between the effectiveness of the compounds is the larger number of improvers in the chloroquine group $(21 / 30$ or $21 / 26$ if non-drugrelated withdrawals are excluded) as compared with the dapsone group (12/30 or $12 / 29)$.

Antimalarials were not firmly established as effective agents until publication of the long-term studies by Freedman and Steinburg ${ }^{3}$ and Popert et al. ${ }^{4}$ in 1961 , whose patients given $250 \mathrm{mg}$ per day showed significant improvements in disease activity, grip strength, ESR, and sheep cell agglutination test (SCAT) titres, and less (nonsignificant) radiological progression. Mainland and Sutcliffe ${ }^{5}$ found similar clinical and laboratory advantages but no influence on radiological progression.

The main anxiety with chloroquine has been the occasional occurrence of retinal toxicity, but the recent survey by Marks ${ }^{6}$ should, subject to reasonable precautions, especially regarding dosage, dispel this anxiety.

In 1976 McConkey et al. ${ }^{1}$ reported a one-year open study on dapsone treatment of 71 patients with RA, later extended ${ }^{7}$ to compare with groups treated for 140 days with prednisone and gold. Dapsone and gold induced similar clinical improvement, with gradual and progressive decrease of ESR and CRP.

The first placebo controlled study of dapsone was reported by Swinson et al. ${ }^{8}$ in 1981 . The dapsone treated group showed significant clinical improvement and reduced ESR, CRP, and plasma viscosity. Of the 22 patients in the dapsone group 19 completed the 14-week study period, the dropouts being due to rash, leucopenia, and nausea. The mean heamoglobin level fell by $1 \mathrm{~g} / \mathrm{dl}$ in the dapsone group, with the nadir at 6 weeks and recovering thereafter. It was considered that the tendency to cause haemolysis would be the main limiting factor in its usage. Our findings with dapsone were very similar to those of 
Swinson et al. ${ }^{8}$ with significant improvement in similar clinical and laboratory parameters on the same time scale.

The major difference between our study and the other reported studies is the relatively large number of dropouts in our dapsone group, either for lack of efficacy or haemolytic decrease in haemoglobin level. There is no doubt that this latter factor was in part related to our own lack of experience with dapsone as well as our close scrutiny of each patient's progress, so that poor response was quickly recognised. There was no indication that dapsone response or intolerance was related to acetylator status (Crook P R, et al., submitted for publication).

Our conclusions, however, are clear. Both dapsone and chloroquine are effective preparations. In our study chloroquine was the more effective and certainly the better tolerated and is generally a much easier drug to manage. So we would regard chloroquine as the preferred treatment for patients with active or progressive disease not controlled by nonsteroidal anti-inflammatory drugs, with dapsone as an alternative for patients who fail to respond to or are unable to tolerate chloroquine.

We thank Mrs S. Clarke, Mrs J. Fisher, Mrs D. Frost, and Mrs R. Jackson, for clinical assistance, Dr T. E. Hothersall for allowing us to study his patients, and Mrs V. Garner for perseverence with the manuscript.

This work was supported in part by a grant from the Arthritis and Rheumatism Council.

\section{References}

1 McConkey B, Davies P, Crockson R A, Butler M, Constable T J. Dapsone in rheumatoid arthritis. Rheumatol Rehabil 1976; 15: 230-4.

2 Sharp J T, Lidsky M D, Collins L C, Moreland J. Methods of scoring the progression of radiological changes in rheumatoid arthritis. Arthritis Rheum 1971; 14: 706-20.

3 Freedman A, Steinburg V L. Chloroquine in rheumatoid arthritis: a double-blindfold trial of treatment for one year. Ann Rheum Dis 1960; 19: 243-50.

4 Popert A J, Meijers K A E, Sharp J, Bier F. Chloroquine diphosphate in rheumatoid arthritis: a controlled trial. Ann Rheum Dis 1961; 20: 18-33.

5 Mainland D, Sutcliffe M I. Hydroxychloroquine sulphate in rheumatoid arthritis: a six month double blind trial. Bull Rheum Dis 1962; 13: 287.

6 Marks J S. Chloroquine retinopathy: is there a safe daily dose? Ann Rheum Dis 1982; 41: 52-8.

7 McConkey B, Davies P, Crockson R A, et al. Effects of gold, dapsone, and prednisone on serum C-reactive protein and haptoglobin and the erythrocyte sedimentation rate in rheumatoid arthritis. Ann Rheum Dis 1979; 38: 141-4.

8 Swinson D R, Zlosnick J, Jackson L. Double blind trial of dapsone against placebo in rheumatoid arthritis. Ann Rheum Dis 1981; 40: 235-9. 